\title{
The menisci and joint capsule of knee joint in New Zealand Rabbit
}

\author{
M.Erdem GÜLTIKKEN ${ }^{1}$, İ.Önder ORHAN ${ }^{2}$, R.Merih HAZIROĞLU ${ }^{2}$ \\ ${ }^{1}$ Department of Anatomy, Faculty of Veterinary Medicine, University of Ondokuzmayis; ${ }^{2}$ Department of Anatomy, Faculty of \\ Veterinary Medicine, University of Ankara.
}

\begin{abstract}
Summary: The aim of this study was to reveal the anatomic features of the joint capsules and meniscus in the knee joint of adult New Zealand rabbits and to provide data for the other researchers. The cranial femoropatellar compartment lying distally between the patella and the patellar ligament was observed widening on the proximal aspect of the infrapatellar adipose body filling this space between the patellar ligament and tuberositas tibia. This location was determined to be the most suitable space for intracapsular injection. Latex was injected into the joint to assess the limits of the joint capsule and its connections. The cavities in the knee joint of the rabbit were seen to be connected with each other. The cavities in the joint capsule widening on the proximal aspect of the infrapatellar adipose body were displayed coursing in the cranio-caudal direction on both sides and providing a passage for the lateral and medial femorotibial compartments.
\end{abstract}

Key words: Anatomy, joint capsule, menisci, rabbit.

\section{Yeni Zelanda tavşanı diz ekleminde meniscus articularis ve capsula articularis}

Özet: Bu çalışmada Yeni Zelanda Tavşanı diz ekleminde bulunan meniscus ve eklem kapsülünün anatomik özelliklerini belirlemek ve diğer araştırmacılara kaynak sağlamak amaçlandı. Patella ve lig. patellae ile femur arasında distal'e doğru uzanan cranial femoropatellar kompartmanın, ligamentum patellae ile tuberositas tibiae arasını dolduran corpus adiposum infrapatellare'nin proximal'inde genişleyerek yayıldığı görüldü. Bu noktanın intrakapsüler enjeksiyon için en uygun yer olduğu tespit edildi. Tavşanlarda eklem boşluğu içerisinde yer alan kompartımanların birbirleriyle ilişsili olduğu görüldü. Corpus adiposum infrapatellare'nin proximal'inde genişleyen eklem kapsülünün içinde kalan boşlukların her iki yanda cranial'den caudal'e doğru seyrederek lateral ve medial femorotibial kompartmanlara geçiş sağladığı tespit edildi.

Anahtar sözcükler: Capsula articularis, makroanatomi, meniscus, tavşan.

\section{Introduction}

The knee joint is a compound joint that includes the femorotibial joint (between the condyles of the femoral and the tibial bones), the femoropatellar joint (between the trochlea of the femoral bone and the patellar bone) and the proximal tibiofibular joint (between the condylus lateralis of the tibial bone and the caput fibulae) $(4,6,9$, $10,12)$. The concordance, between the inharmonious articular surfaces of the condyles of femur and tibia, is provided by the menisci. The menisci fixed on the condyles of the tibia form the articular cavity that would prevent the condyles of the femur from emerging. The articular capsule of the knee joint contains synovial fluid providing slipperiness which decreases friction between the bones $(4,7,11)$.

The articular capsule is formed by connective tissue which envelops the joint entirely $(2,3)$. The articular capsule consists of two layers as fibrous membrane and synovial membrane which are different in function and structure $(8,10,11)$. Fibrous membrane connects both the convex edge of menisci and the border of the articular surfaces and continues with periosteum. Cranially it is strengthened with patellar retinacula. Caudally it is connected with caudal cruciate ligament and meniscofemoral ligament of lateral meniscus (13). Synovial membrane covers the area between two pairs of condyles. The cruciate ligaments exist in the synovial membrane in the middle of the knee joint and partly divide the articular cavity into medial and lateral compartments (11).

Experimental studies that involve easily reproducible animals (rabbits, rats or guinea pigs) emphasized the importance of the rabbit. In the literature there are few studies that involve detailed information about the knee joint of the rabbit which is a frequently used experimental animal. The aim of the present investigation is to describe the morphology of the knee joint of New Zealand Rabbit with emphasis on menisci, joint capsule, joint cavities and patellar retinacula.

\section{Materials and Method}

A total of 20 normal knee joints that belonged to 5 male and 5 female adult New Zealand rabbits that were ranging from $2100 \mathrm{gr}$ to $2550 \mathrm{gr}$ (female rabbits 2300 
\pm 200 gr, male rabbits $2350 \pm 200$ gr) which were sacrificed for different researchers were used in the study. The joint cavity of knee joint was located and a canule was inserted into the joint capsule from the lateral side of the patellar ligament. The latex (ZPK-580-S. Gerrard Biological Center, England) which was colored with blue drawing ink (Rothring GmbH, D-22510, Germany) was injected. The knee joint were made flexion - extension 25 times, as the description of Desrochers et al (1996), in order to obtain the latex to be penetrated totally in the articular cavity. The materials were left in water at $+4{ }^{\circ} \mathrm{C}$ for 12 hours for the latex to be polymerized. Then they were transferred to $10 \%$ formaldehyde solution. Dissection was performed under an Olympus MTX stereomicroscope (Olympus MTX No. 20326, Olympus Optical Co. Ltd., Japan).

The measurements of menisci were evaluated in four groups (female, male, right and left). The data obtained from menisci measurements was subjected to the Mann-Whitney test for two independent samples using SPSS 10.0 program. Results were considered as significant when $\mathrm{P}$ values were less than 0.05 .

\section{Results}

The menisci, joint capsule, patellar retinacula and the muscular connections of the knee joint were investigated respectively.

\section{Lateral meniscus}

The lateral meniscus (meniscus lateralis), which takes place between the lateral condyles of the femur and tibia, was crescent-shaped and its concave face was towards the medial side. Its medial side was thin, got thick towards the lateral side (Figure 1).

Cranial meniscotibial ligament of the lateral meniscus (lig. meniscotibiale craniale menisci laterale), originated from the cranial border of the lateral meniscus, was determined to be tied up the articular surface of the medial condyle of the tibia at the craniomedial side of the

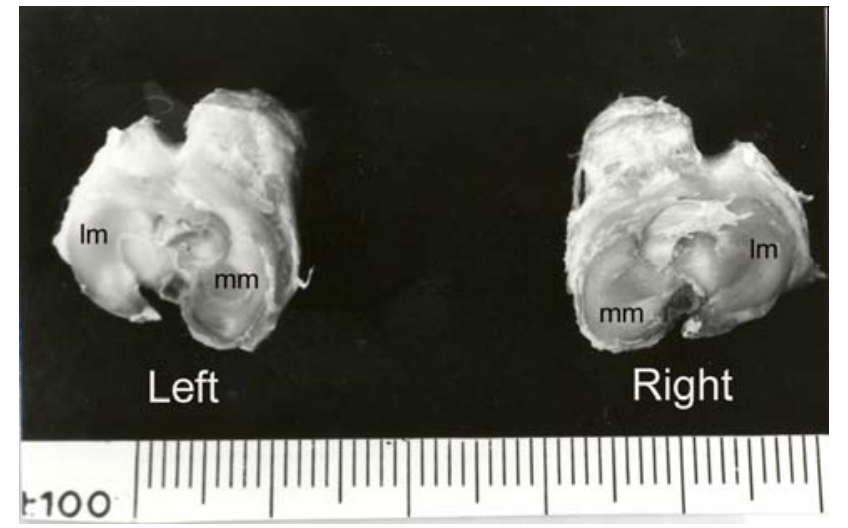

Figure 1. Photograph of the proximal part of the tibia - superior aspect.

Şekil 1. Tibia'nin proximal kesiminin üstten görünümü.

Lateral meniscus $(1 \mathrm{~m}) \quad$ Medial meniscus (mm)

intercondylar area (area intercondylaris centralis). Meniscofemoral ligament (lig. meniscofemorale) emerging from the caudal part of the lateral meniscus connected the lateral meniscus to the medial condyle of the femur. It was determined that joint capsule was very strong caudally and connected lateral meniscus to the tibia. Morphometric data on the lateral meniscus are listed in Table 1. The mean thickness of cranial part of lateral meniscus was $2.53 \pm 0.28 \mathrm{~mm}$; caudal part was $2.16 \pm 0.30 \mathrm{~mm}$ and cranio-caudal diamater was $9.17 \pm$ $0.72 \mathrm{~mm}$. Thus in the all examined samples the thickness of caudal part was significantly thinner in female ( $p \leq$ 0.01). Cranio-caudal diameter was longer in males (left side $\mathrm{p} \leq 0.05$, right side $\mathrm{p} \leq 0.01$ ). No statistical difference was found between male and female on the thickness of cranial part $(\mathrm{p} \geq 0.05)$.

\section{Medial meniscus}

Medial meniscus (meniscus medialis) took places between the medial condyles of the femur and tibia, was found to be bigger than lateral meniscus (Figure 1). Crescent-shaped medial meniscus was noted to be connected to the tibia cranially by the cranial

Table 1. Parameters of the right and left menisci (mm; mean \pm SD)

Tablo 1. Meniscus lateralis ve meniscus medialis'e ilişkin metrik değerler (mm; mean $\pm \mathrm{SD}$ )

\begin{tabular}{|c|c|c|c|c|c|}
\hline & \multicolumn{2}{|c|}{ Male $(\mathrm{n}=5)$} & \multicolumn{2}{|c|}{ Female $(n=5)$} & \multirow[b]{2}{*}{ General mean } \\
\hline & Right & Left & Right & Left & \\
\hline \multicolumn{6}{|l|}{ Meniscus Lateralis } \\
\hline Thickness of cranial part & $2.47 \pm 0.23$ & $2.67 \pm 0.20$ & $2.31 \pm 0.14$ & $2.68 \pm 0.36$ & $2.53 \pm 0.28$ \\
\hline Thickness of caudal part & $2.27 \pm 0.13$ & $2.56 \pm 0.14$ & $1.84 \pm 0.08$ & $1.96 \pm 0.08$ & $2.16 \pm 0.30$ \\
\hline Cranio-caudal diameter & $9.37 \pm 0.27$ & $9.95 \pm 0.52$ & $8.39 \pm 0.39$ & $8.98 \pm 0.62$ & $9.17 \pm 0.72$ \\
\hline \multicolumn{6}{|l|}{ Meniscus medialis } \\
\hline Thickness of cranial part & $2.51 \pm 0.19$ & $2.68 \pm 0.26$ & $1.93 \pm 0.34$ & $2.17 \pm 0.18$ & $2.32 \pm 0.38$ \\
\hline Thickness of caudal part & $1.56 \pm 0.15$ & $1.69 \pm 0.18$ & $1.14 \pm 0.10$ & $1.24 \pm 0.08$ & $1.41 \pm 0.26$ \\
\hline Cranio-caudal diameter & $9.82 \pm 0.54$ & $10.64 \pm 0.76$ & $8.92 \pm 0.27$ & $8.99 \pm 0.49$ & $9.62 \pm 0.86$ \\
\hline
\end{tabular}


meniscotibial ligament of the medial meniscus (lig. meniscotibiale craniale menisci mediale) and caudally by the caudal meniscotibial ligament of the medial meniscus (lig. meniscotibiale caudale menisci medialis). Also, it was determined that medial meniscus attached to the caudomedial border of the joint capsule and thus the joint capsule supported the medial meniscus caudomedially. Besides, lateral border of the meniscus connecting the joint capsule was found to be thick. It was seen that the thickness of the meniscus was getting less from cranially to the caudally and measured to be $2.32 \pm 0.38 \mathrm{~mm}$ cranially and $1.41 \pm 0.26 \mathrm{~mm}$ caudally. The craniocaudal diameter of the meniscus was measured $9.62 \pm$ $0.86 \mathrm{~mm}$ (Table 1). Statistically significant differences between the male and female were determined in the thickness of cranial part (left side $\mathrm{p} \leq 0.05$, right side $\mathrm{p} \leq$ 0.01 ), the thickness of caudal part and cranio-caudal diameter $(\mathrm{p} \leq 0.01)$.

\section{Joint capsule}

On examination, it was noted that joint capsule (capsula articularis) consisted of two separate membranes as synovial and fibrous. The synovial membrane was observed as a thin layer attaches to the border of articular surface. Fibrous membrane was formed by the collagen fibers of net-shaped and progressed to the joint capsule apart from the infrapatellar adipose body. The joint capsule connected to the femur, patella and tibia was observed to be progressed with periosteum.

The articular cavity of three compartments of knee joint connected each other as cranial femoropatellar compartment, lateral femorotibial compartment and medial femorotibial compartment. Cranial femoropatellar compartment, which took place between the trochlea of the femoral bone and patella, was found to be extended proximally between the femur and the quadriceps femoris muscle and ended at the proximal border of the suprapatellar cartilage. It was determined that the compartment located among the patella, the patellar ligament and femur and extended distally as far as at the proximal part of the infrapatellar adipose body filling between the patellar ligament and the tibial tuberosity. Also, the joint capsule was noted to be gone forward from cranially to caudally at the proximal part of the infrapatellar adipose body and provided a passage to the lateral and medial femorotibial compartments.

The joint capsule, which was anteriorly begun from the edge of the trochlea of the femoral bone connected to the proximal border of the menisci. It was also continued to downward from the distal border of the meniscus and ended on the lateral condyle of tibia. The lateral and medial borders of the joint capsule were formed by collateral ligaments.
The joint capsule was caudally separated into two parts as lateral and medial by cranial and caudal cruciate ligaments. Proximally, the joint capsule was found to be begun from the edge of the articular surfaces of sesamoids of the femur and extended distally connecting to the edge of the sesamoid bones. Distally, the joint capsule was observed to be connected to the proximal border of the menisci and continued among the menisci, collateral ligaments and tibia (Figure 2).

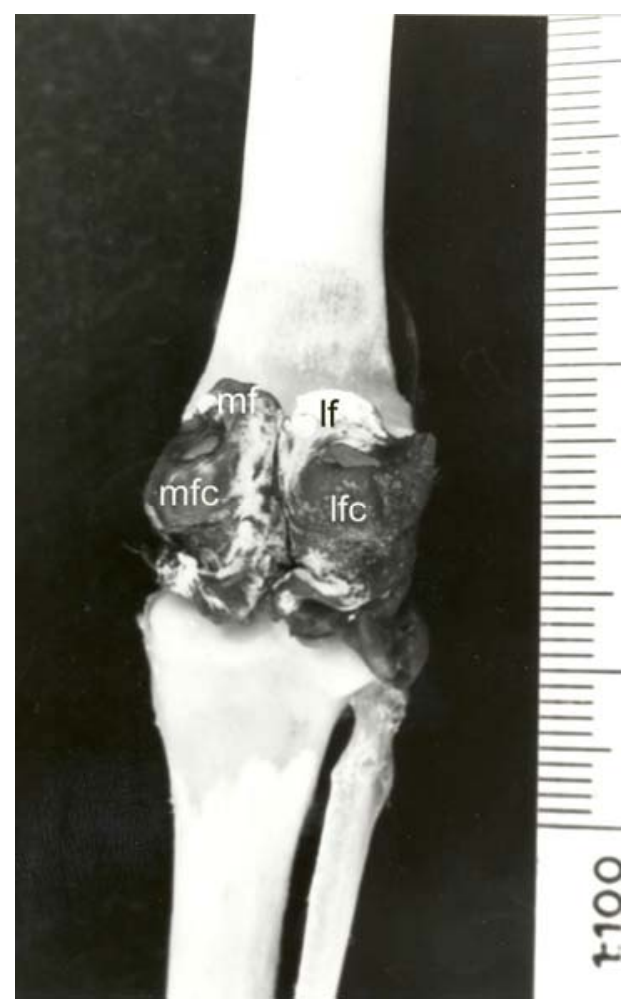

Figure 2. Photograph of the knee joint - caudal aspect Şekil 2. Diz ekleminin caudal'den görünümü

The edge of the lateral (lf) and medial fabella (mf), lateral femorotibial compartment (lfc) and medial femorotibial compartment (mfc)

The lateral femorotibial compartment, took place between the lateral condyles of the femoral and the tibial bones, was bordered medially by the caudal cruciate ligament, laterally by the lateral collateral ligament, proximally by lateral fabella (os sesamoideum musculi gastrocnemii lateralis) and distally by lateral condyle of the tibial bone. It was also observed that proximal cavity formed between the condyles of femur and the menisci, was bigger than distal cavity formed between the tibia and the menisci. At the caudal part of the lateral collateral ligament, lateral femorotibial compartment formed a protruding connecting the superior part of the articular cavity of the proximal tibiofibular joint.

It was seen that the part of the joint capsule, which was connected to the lateral side of the popliteal fabella (os sesamoideum musculi poplitei), wass attached to the 
femur and the edge of the tendon of the popliteal muscle. At the proximal part, the joint capsule attached to the border of lateral fabella. Also it attached to the popliteal fabella and to the tibia beginning at the level of popliteal notch (incisura poplitea).

It was seen that lateral femorotibial compartment distally formed an extension on the sulcus extensorius together with the synovial sheath which surrounded the tendon of the extensor digitorum longus muscle (Figure 3).

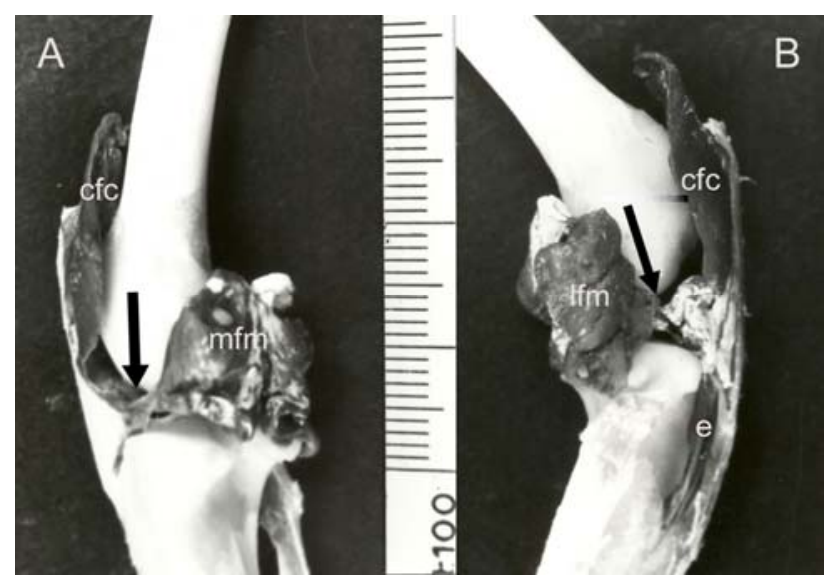

Figure 3. Photograph of the knee joint - medial (A) and lateral (B) aspects.

Şekil 3. Diz ekleminin medial (B) ve lateral (A)'den görünümü. Cranial femoropatellar compartment (cfc), provided a passage (arrow) to the lateral femorotibial compartment (lfc) and medial femorotibial compartment (mfc). Lateral femorotibial compartment (lfc) distally forms an extension (e) on the sulcus extensorius.

The medial femorotibial compartment was took place between the medial condyles of the femoral and tibial bones. Medial femorotibial compartment was surrounded laterally by caudal cruciate ligament, medially by medial collateral ligament, proximally by lateral fabella and distally by medial condyle of tibial bone. This compartment divided into proximal and distal parts by the medial meniscus. The distal part was a thin layer between the meniscus and tibial bone. As for the proximal part, it formed the mean compartment.

\section{Patellar retinacula and muscular connections}

The middle part of the tendon of the quadriceps femoris muscle which wass inserted to the patella was formed by the fibers of tendon of the rectus femoris muscle and the vastus intermedius muscle. The medial and lateral parts of the tendon, formed by the aponeurosis of the vastus medialis and vastus lateralis muscles, were attached to the medial and lateral borders of the patella respectively. Besides, the apex of patellar bone connected to the tibial tuberosity by the patellar ligament which continued distally of the tendon of the quadriceps femoris.
Patellar retinacula was found to be consisted of two parts as medial and lateral retinacula of patella. It formed by vertical fibers of superficial and deep layers. The superficial layer of medial retinacula was formed by the tendons of sartorius and gracilis muscles and attached to the medial border of patellar bone, to the patellar ligament and to the cranio-medial part of the medial condyle of tibial bone. The deep layer of the medial retinacula was formed by the aponeurosis of the vastus medialis muscle and the tendon of semimembranosus muscle. The fibers arising from semimembranosus muscle were determined to be attached to the medial epicondyle of the femur and to the medial condyle of the tibia. Some of these fibers were continued together with the medial collateral ligament and medial meniscus.

The lateral retinacula of the patella was formed by the proximal parts of the superficial and deep layers. Also, the distal part of the lateral retinacula was established to be attached to the tibial tuberosity by the lateral border of patellar ligament and this part was observed to be formed as a single layer. The tendon of biceps femoris muscle was determined to be connected to the lateral part of the patellar bone and patellar ligament beginning from the tibial tuberosity. Also, lateral retinacula was attached to the head of the fibula (caput fibulae) by the fibular connection of the cranial part of the biceps femoris muscle.

It was observed that the cranial femoropatellar compartment of the joint capsule was reinforced by patellar retinacula.

The fibers, originated from the tensor fasciae latae muscle and fascia lata, were observed to be mixed into the cranial and caudal aponeurosis of biceps femoris muscle and continued with crural fascia.

\section{Discussion and Conclusion}

New Zealand rabbits are being used as a model for the studies; however there are limited numbers of published papers about knee joints in these experimental animals. It has been informed that joint capsule covers the joint among lateral fabella in the carnivores which its menisci and joint capsule are similar with the rabbit. The joint capsule also forms a pouch proximally at both sides under quadriceps femoris muscle in domestic animals (11). As for the rabbit, joint capsule was divided into two parts between the lateral fabella and the caudal cruciate ligament and it did not form a pouch under the suprapatellar cartilage.

Nickel et al. (11) pointed out that synovial membrane covers the area which is between the two pairs of condyles and divides the articular cavity into lateral and medial compartments. They also determined that 
these synovial compartments are connected with each other in carnivores and ruminant but not in equidae. Desrochers at al. (6) figured out that lateral femorotibial articular cavity does not connect to the two other articular cavities in $34.2 \%$ of cow. Vacek et al. (14) determined that in the horse there is no specific connection between the articular compartments and there is connection, which differs according to individuals, between femoropatellar and medial femorotibial compartments. While, there is less connection to the lateral femorotibial compartment. In the study, we have determined that in the rabbit, three compartments forming articular cavity were connected with each other in all examined specimens.

Biceps femoris muscle of the rabbit is attached to the patella disto-laterally of the femoral bone $(1,5)$ and does not have any attachments to the fibula and tibia (5). In the present study biceps femoris muscle was found to be attached to the patellar ligament and lateral part of the patellar bone beginning from the tuberositas tibia.

Desrochers et al. (6) informed that in the cattle the connection of femoropatellar joint to the lateral and medial femorotibial joint is formed by the distal part of abaxial face of the trochlea of the femoral bone. In the rabbit, it was seen that femoropatellar articular cavity went forward from cranial to the caudal part at the level of the infrapatellar adipose body and connected to the lateral and medial femorotibial articular cavity.

Prose (13) have stated that fibrous capsule is attached strongly to the peripheral borders of the menisci, and the lateral side of this attachment is interrupted by the tendon of the extensor digitorum longus muscle and the popliteal fabella in the cat. In our study, the same findings were found for the rabbit.

The cranial femoropatellar compartment, which extended distally along the patella, the patellar ligament and femoral bone, was observed to be spread widening proximally of the infrapatellar adipose body filling between patellar ligament and tuberositas tibia. This point was found to be the most appropriate area for intracapsular injection. In this study, we have determined that in the rabbit, articular cavities of the knee joint connected to each other and the joint capsule widening at the proximal part of infrapatellar adipose body extended caudally at both sides and provided a passage to the lateral and medial femorotibial compartments.

\section{References}

1. Alpak H, Kahvecioğlu O, Çakır M, Özcan S (1998): Tavşanlarda articulatio genus'un femoropatellar ve collateral ligamentleri üzerinde makro-anatomik çalışmalar. İstanbul Üniv Vet Fak Derg, 24, 5-21.

2. Billings E, Von Schroeder HP, Mai MT, Aratow M, Amiel D, Woo LY, Coutts RD (1990): Cartilage resurfacing of the rabbit knee. Acta Orthop Scand, 61, 201- 206.

3. Bland YS, Doreen EA (1997): Fetal and postnatal development of the patella, patellar tendon and suprapatella in the rabbit; changes in the distribution of fibrillar collagens. J Anat, 190, 327-342.

4. Craigie EH (1969): Bensley's Practical Anatomy of the Rabbit, An Elementary Labaratory Text-book in Mammalian Anatomy. $7^{\text {th }}$ ed, University of Toronto Press, Toronto.

5. Crum JA, Laprade RF, Wentorf FA (2003): The anatomy of the posterolateral aspect of the rabbit knee. $\mathrm{J}$ Orthop Res, 21, 723-729.

6. Desrochers A, St-Jean G, Cash WC, Hoskinson JJ, Dcbowes RM (1996): Characterization of anatomic communications between the femoropatellar joint and lateral and medial femorotibial joints in cattle, using intraarticular latex, positive contrast artrography, and fluoroscopy. AJVR, 57, 798-802.

7. Dursun N (2000): Veteriner Anatomi I, Medisan Yayınevi, Ankara.

8. Fitch RB, Montgomery RD, Milton JL, Garrett PD, Kincaid SA, Wright JC, Terry GC (1995): The intercondylar fossa of the normal canine stifles: an anatomic and radiographic study. Vet Surg, 24, 148-155.

9. Hebel R, Stromberg MW (1976): Anatomy of The Laboratory Rat. The Williams \& Wilkins Company, Baltimore, USA.

10. Mc Laughlin CA, Chiasson RB (1979): Laboratory Anatomy of the Rabbit, 2nd ed, Wm. C. Brown Company Publishers Dubuque, Iowa.

11. Nickel R, Schummer A, Seiferle E (1986): The Lokomotor System of The Domestic Mammals, Volume I. Verlag Paul Parey, Berlin, Hamburg.

12. Orhan IO, Haziroglu RM, Gultiken ME (2005): The ligaments and sesamoid bones of knee joint in New Zealand rabbits. Anat Histol Embryol, 34, 65-71.

13. Prose LP (1984): Anatomy of the knee joint of the cat. Acta Anat, 119, 40-48.

14. Vacek JR, Ford TS, Honnas CM (1992): Communication between the femoropatellar and medial and lateral femorotibial joints in horses. AJVR, 53, 1431-1434

Geliş tarihi: 12.12.2005 / Kabul tarihi: 02.07.2007
Address for correspondance
Dr. M. Erdem Gultiken
Department of Anatomy, Faculty of Veterinary Medicine,
University of Ondokuz Mayls
55139 Kurupelit / Samsun - Türkiye
e-mail : erdemg@omu.edu.tr 